\title{
Erratum to: Economic Effects of the Modern Information Service Industry in China: Evidence from Beijing
}

Fenfei Chen, Chenchen Wang and Yuan Ren

Erratum to:

Chapter "Economic Effects of the Modern Information Service Industry in China: Evidence from Beijing" in: M. Li et al. (eds.), Proceedings of 2015 2nd International Conference on Industrial Economics System and Industrial Security Engineering, DOI 10.1007/978-981-287-655-3_28

The book was inadvertently published with an incorrect surname of one of the authors as "Anderdassen" whereas it should be "Andergassen" in the reference section. The erratum book and the reference has been updated.

The updated original online version for this chapter can be found at DOI 10.1007/978-981-287-655-3_28

F. Chen $(\bowtie) \cdot$ C. Wang $\cdot$ Y. Ren

School of Economics and Management, Beijing Jiaotong University,

Beijing 100044, China

e-mail: ffchen@bjtu.edu.cn

C. Wang

e-mail: 12120510@bjtu.edu.cn

Y. Ren

e-mail: 13120498@bjtu.edu.cn

F. Chen

Beijing Center for Industrial Security and Development Research,

Beijing Jiaotong University, Beijing 100044, China 